\title{
CRIANÇAS E INFÂNCIA NA INTERFACE DA SOCIALIZAÇÃO. QUESTÓES PARA A EDUCAÇÁO INFANTIL
}

\author{
CHILDREN AND CHILDHOOD IN THE INTERFACE OF \\ SOCIALIZATION. ISSUES TO EARLY CHILDHOOD EDUCATION
}

\author{
Lisandra Ogg Gomes \\ Doutorado em Educaçáo, Universidade do Estado do Rio de Janei- \\ ro (UERJ). Rio de Janeiro, Rio de Janeiro - Brasil \\ ORCID: https://orcid.org/0000-0002-3601-7758 \\ lisandraogg@yahoo.com.br
}

Ligia Maria Leão de Aquino

Doutorado em Educaçáo, Universidade do Estado do Rio de Janeiro (UERJ). Rio de Janeiro, Rio de Janeiro - Brasil ORCID: https://orcid.org/0000-0002-8767-7203

ligiaaquino@yahoo.com.br

Resumo: De um lado, teorias e documentos acerca das crianças as legitimam como sujeitos de direitos e agentes sociais, e ainda que haja um hiato entre discursos e práticas para a infância, crianças e sociedade, já é possível perceber que as crianças devem ser o centro do trabalho político e pedagógico. De outro lado, as atuais teorias de socialização apontam para um processo que é significado pelos indivíduos, implicando tensōes e determinaçóes, açôes e discursos contraditórios e difusos e embates de interesses e interações entre geraçóes, indivíduos e instituiçóes. A escola de educação infantil, os grupos de pares, a família e a mídia sáo instituiçôes importantes na infância, porque possibilitam para as crianças encontros, participaçóes e atuaçóes sociais. Com este texto, pautado no referencial teórico dos Estudos da Infância, pretendemos tratar das dinâmicas e articulaçôes entre crianças e seus processos de socialização, com o propósito de oferecer uma contribuição sobre os sentidos socioculturais produzidos nessa interface.

Palavras-Chave: Crianças; Infância; Processos de Socialização.

Aвstract: On one hand, theories and documents about children legitimize them as individuals with rights and social agents. Even if there is a gap between discourses and practices focused on childhood, children, and society, it's possible to see that children are in center of the political and pedagogical work. On the other hand, current socialization theories point to a process that is geared by the individuals, implicating in tensions and determinations, actions and contradictory and diffuse discourses, and clashes of interests 
and interactions between generations, individuals, and institutions. The early childhood education, the peers groups, family, and midia are important institutions in childhood because allows children to meet and act socially. With this text, based in Childhood Studies, we intend to deal with the dynamics and articulations between children and their socialization processes aiming to offer a contribution on the socio-cultural senses produced in this interface.

KEYwords: Children; Childhood; Processes of Socialization.

Sou apenas uma criança e não tenho as soluçóes, mas quero que saibam que vocês também não têm. Vocês não sabem como reparar os buracos da camada de ozônio. Vocês não sabem como salvar os salmóes de águas poluídas. Vocês não podem ressuscitar os animais extintos. Vocês não podem recuperar as florestas que um dia existiram onde hoje é deserto. Se vocês náo podem recuperar nada disso, então por favor parem de destruir!

(Severn Cullis-Suzuki, I2 anos, trecho de seu discurso na ECO-92)

Eu falo não por mim, mas por aqueles cujas vozes não podem ser ouvidas. Por aqueles que têm lutado por seus direitos. $\mathrm{O}$ seu direito de viver em paz. O seu direito de ser tratado com dignidade. $\mathrm{O}$ seu direito à igualdade de oportunidades. $\mathrm{O}$ seu direito de ser educado.

(Malala Yousafzay, I6 anos, trecho de seu discurso na ONU pelo direito das mulheres à educação, 2013)

Somos Sem Terrinha do MST, seres humanos, crianças filhas dos Sem Terra que estão nos acampamentos e assentamentos do Estado do Rio de Janeiro. Lutamos por nossos direitos e queremos viver, morar, brincar e estudar no campo, ajudando no cultivo e nas colheitas de nossas produçóes.

(Leitura da Carta das Crianças Sem Terrinha do Estado do Rio de Janeiro em audiência pública na ALERJ, como parte da XX Encontro Estadual dos Sem Terrinha, em outubro de 20I7)

Nós, crianças, estamos fazendo de tudo para acordar os adultos. Nós, crianças, fazemos tudo isso porque queremos que eles 
ajam. Nós, crianças, fazemos isso porque queremos recuperar nossos sonhos e nossa esperança.

(Greta Thunberg, 16 anos, trecho de seu discurso na Piazza del Popolo, Roma, em um protesto contra as mudanças climáticas, movimento "Greve Escolar pelo Clima", 2019)

Essas passagens, de casos emblemáticos de crianças, jovens e grupos de militantes, trazem um pouco do exercício político da infância enquanto coletivo que resiste de diferentes formas e o papel que crianças e infância vêm aos poucos ocupando e conquistando na sociedade, o qual se mostra atuante, legítimo e presente. Temos visto com frequência - talvez pela maior difusão em diferentes mídias -, na sociedade contemporânea, manifestaçóes e expressóes de crianças e adolescentes reivindicando seus interesses, direitos, escutas, ideias, dessa forma marcando seu ativo papel social. Certamente são açôes e discursos que já fazem parte de uma militância política que percebe que todos são impactados, quase sempre de forma negativa, quando as mudanças estruturais são antidemocráticas e imperiais, e não consideram minorias nem direitos essenciais, entre eles os da infância. O que temos vivido, no caso brasileiro, é uma pluralidade de espaços e de sentidos sociais, ainda que em um tempo de incertezas e retrocessos, que tecem modos de ser a partir de vivências e experiências socializadoras diversas. Nesse nosso tempo, a escola e a família comporiam com outras instâncias e meios sociais - como a mídia, grupos de pares, igreja e similares - as experiências individuais desses atores sociais, agentes sociais ativos que vivem, na atualidade, situaçôes relativamente heterogêneas ao se confrontarem com as normas sociais, ter outras maneiras de ver, sentir e agir, outros gostos e preferências. (LAHIRE, 2006)

Nesse contexto, falar de crianças, socialização e educação ainda é tema atual e relevante neste século XXI, porque é uma questão que perpassa a infância, sobretudo diante da complexidade e diversidade tanto de suas açóes quanto de seus sentidos. Temos em consideração que ninguém será contra a necessidade de apresentar os diferentes aspectos e a diversidade da sociedade às crianças; que educação é socialização, ação compartilhada e mediatizada coletivamente; e a escola de educação infantil é um espaço fundamental nesse processo, para a infância e as crianças. Como bem aponta Maria da Graça Setton (20II), a socialização, no contempo- 
râneo, é um espaço plural de múltiplas referências identitárias, não apenas um processo de relaçôes assimétricas, unidirecionais e verticais. Da mesma forma, torna-se cada vez mais domínio comum, em razão das investigações acadêmicas desenvolvidas na esfera dos direitos, que as crianças são capazes e formulam seus conhecimentos a partir das experiências e interaçôes que estabelecem nos seus meios sociais. Por fim, é categórico que a escola de educação infantil representa um espaço da infância e um direito das crianças, ainda que seja preciso continuar a lutar por sua qualidade e pelo acesso a essa educação para todas elas.

Então, por que retomar questóes que parecem estar esclarecidas para o conjunto da sociedade? Por que ainda são relevantes e atuais essas temáticas? Uma coisa é entender esses conceitos a partir de suas formulaçôes, outra é entendê-los a partir das intervençóes da cultura, da política e da própria educação. Por isso, como nos aconselha Paulo Freire (1988), as experiências devem ser reinventadas: devemos descobrir, em função do nosso conhecimento tão rigoroso quanto possível da realidade, como aplicar de forma diferente um mesmo princípio válido do ponto de vista de nossa opção política.

Nesse sentido político, não nos parece possível continuar a pensar sobre e com as crianças e a infância sem entender seus limites, suas formas de resistência, suas atuações, participações e dimensôes. No formato de um ensaio exploratório, buscamos uma reflexâo teórica que nos dê subsídios para entender esses sujeitos sociopolíticos nas suas relaçóes com as instituiçôes socializadoras.

\section{As crianças, a infância e o socializar-se}

A constituição dos estudos da infância, a partir de ideias políticas e investigaçóes sensíveis ao mundo das crianças, tratou de visibilizar perspectivas macro e micro a respeito dessa geração e desses sujeitos. Em outras palavras, as investigaçóes tanto abarcaram as questóes da infância e seu modo de desenvolvimento quanto as crianças com suas formas de atuaçáo e seus modos de pensar em comparaçáo com as demais geraçóes. Para além dos adultos perguntarem sobre o futuro das crianças e como melhor prepará-las para isso, a complexidade dos estudos da infância teve 
importância porque passou a contemplar e buscar entendê-las enquanto são crianças e como membros da infância (QVORTRUP, 20Io). Essa outra perspectiva de compreensão e investigação colocou em contratempo a naturalização da infância e a recusa de uma representação da criança como alguém que terá importância somente quando superar essa fase da vida e tornar-se adulto.

Em primeiro lugar, concordamos com o autor que cada criança vive, na sua infância, mudanças significativas conforme suas disposiçôes físicas, cognitivas, emocionais e psíquicas, e também àquelas vinculadas aos determinantes de tempo e espaço em que atuam e participam. Em segundo lugar, essas disposiçóes e os modos como a infância se reorganiza e se transforma estão em relação com sua posição, com suas circunstâncias e condiçôes sociais, econômicas, políticas e culturais. A infância sofre e se transforma em virtude daquilo que afeta a sociedade como um todo, por exemplo, as questóes referentes ao pertencimento racial e étnico, às mudanças socioculturais, climáticas e econômicas, à reestruturação etária, às ideologias, atuaçôes políticas e discursos e às práticas científicas que acabam por modificar as relaçóes sociais. Em outras palavras, infância e crianças não estão à parte na sociedade, mas a constituem. Sendo assim, "O desenvolvimento histórico da infância não acaba com a sua categoria; e a variabilidade cultural da infância contemporânea testemunha em favor da sua presença universal." (QVORTRUP, 2010, p. 637)

$\mathrm{O}$ que queremos afirmar é que a infância e as crianças são importantes agora, no tempo presente, pela posição e função que ocupam no conjunto da sociedade, pelo papel ativo na divisão geracional do trabalho e na construção e determinação de suas vidas, na produção e difusão cultural, na reorganizaçáo e propagação de ideias educacionais e culturais, na política (ainda que latente) e no movimento econômico que gera. A vida das crianças se interconecta com a dos demais sujeitos - adultos, jovens e velhos - colocando-as em uma constante posição de ação e participação nos seus espaços e tempos, e isso garante uma outra compreensáo do conceito de infância e o entendimento de que as crianças são agentes sociais. Portanto, não há, para elas, um momento de entrada na sociedade, pois dela fazem parte desde quando nascem, ou, se pudermos ir um pouco além, desde quando são geradas, visto que são vários os setores e sujeitos que se preparam para a chegada desse novo agente social. 
Como bem indica Jens Qvortrup (2010), a partir de um enfoque estrutural, a infância é uma categoria geracional que constitui a ordem social, ou seja, enquanto construção social, se desenvolve com e no conjunto da sociedade, é permanente mas instável, e não tem um começo e fim temporais, pois a infância continua a existir mesmo depois de as crianças passarem para a geração seguinte. Leena Alanen (200I), que trata dessas questóes a partir de uma abordagem relacional, nos faz notar que há interdependência entre as geraçôes, sobretudo entre crianças e adultos, e que ambos atuam, se afetam e efetuam reestruturaçóes nas suas categorias que podem ser de ordem política, econômica e/ou cultural. Enquanto gerações alteritárias ambas produzem e difundem sentidos, símbolos, ideias e práticas que se tornam culturalmente significativos. Então, podemos afirmar que tanto as crianças quanto os demais sujeitos são agentes sociais que (re) produzem e difundem a cultura a partir das relaçóes estabelecidas intra e intergeracional, e suas açóes e modos de pensar transformam os espaços sociais nos quais se inserem. $\mathrm{O}$ conceito de agência talvez seja mais adequado que o de ator, já que adotaria uma noção mais ampla, "porque não se trata apenas da capacidade de açáo social da criança, mas subentendemse os efeitos dessa mesma ação na definição da situaçáo para os diferentes atores." (BARBOSA; DELGADO; TOMÁS, 2016, p. I I4)

Entendemos que esse modo de compreensão da infância e das transformaçôes na relação com as crianças contaram com alguns elementos difusores e legitimadores, por exemplo, leis e produçóes acadêmicas que colocaram as crianças e a infância em posiçóes de destaque, no centro da questão. Entre as diversas leis, foram promulgadas pelas Organizaçôes das Naçōes Unidas (ONU), em 1959, a Declaração Universal do Direito da Criança; em 1988, a Constituição Federal do Brasil, que ainda é uma referência para as atuais políticas sociais; em 1989, a Convenção Internacional sobre o Direito da Criança (CDC), posteriormente ratificada por 196 países, incluindo o Brasil que, em I990, também implementa o Estatuto da Criança e do Adolescente (ECA), com a lei no 8069. Igualmente, é um marco científico a publicação do livro de Philippe Ariès, em I96I, com sua primeira edição traduzida em 1978 para o português intitulada História social da criança e da família. Além dessa obra, por aqui foi publicado, em I944, o importante artigo, de 2004, do ainda estudante Florestan Fernandes: As "trocinhas" do Bom Retiro. Contribuiçóes do estudo folclórico e sociológico 
da cultura e dos grupos infantis, que, observando crianças de um bairro da cidade de São Paulo, aborda a estrutura dos grupos e do folclore infantis.

Ainda que críticas possam ser feitas a esses materiais, o que eles têm em comum é a articulação entre diferentes campos e sujeitos para o reconhecimento das crianças como seres socioculturais e econômicos vinculados e constituídos a partir de seus contextos; também nos advertem para o fato de que os estudos podem e devem ir além da sociedade adultocêntrica, uma sociedade-centrada-no-adulto, ou, de modo mais específico, uma sociedade-centrada-no-homem-branco-de-classe média (ROSEMBERG, I976). Como bem observam essa autora e Roger Bastide (2004), pelo menos no campo do conhecimento é preciso ir além, propor contribuiçóes interdisciplinares, isto é, uma ciência pode ser esclarecida por ou auxiliar outra, visto que o indivíduo não se desenvolve em um vazio sociocultural. Portanto, é pelas ciências humanas que se apreendem as semelhanças e diferenças do conceito de criança e das necessidades sociais a que responde. Nesse sentido, a construção científica

[...] inspira-se na convicção de que não podemos capturar a lógica mais profunda do mundo social a não ser submergindo na particularidade de uma realidade empírica, historicamente situada e datada, para construí-la, porém, como "caso particular do possível”, conforme a expressão de Gaston Bachelard, isto é, como uma figura em um universo de configuraçôes possíveis. (BOURDIEU, I996, p. I5)

A questão que se coloca nesse pequeno apanhado legal e científico é o fato de as crianças e a infância terem sempre um reconhecimento tardio. Além disso, essa geração e esses sujeitos são os que estão mais expostos aos impactos de qualquer mudança, negativa ou positiva, na estrutura da sociedade. Nas sociedades contemporâneas, esse reconhecimento e a construção sociocultural da infância e das crianças se deram por meio da individualização (subjetivação) e da socialização, nas quais situaçôes, práticas, participaçôes e ideias constituem duas faces de uma mesma moeda, pois tanto as crianças se tornam pessoas da sociedade da qual participam quanto atuam na constituição dessa mesma sociedade. Um processo dotado de diferentes experiências que contribuem para a construção de disposiçóes 
internas, que permitem e orientam a participação na vida social. $\mathrm{O}$ que está posto é a indissociabilidade entre o ser social e o individual.

No entanto, sabemos que: (I) a experiência dos indivíduos é apenas uma fração do "todo social"; (2) essa experiência depende da capacidade (e disposição) de interpretar e interpelar o social; (3) a informação resultante das experiências não pode ser armazenada e posteriormente mobilizada, na sua totalidade, $o$ que supóe processos (intersubjetivos) de seleção, generalização e analogia. (ABRANTES, 20II, p. I22)

O processo de individualização inaugurado com a família moderna - agora voltada para seu interior, para a expressáo do eu de cada membro e para as relaçóes e o investimento afetivo intragrupo, como destaca Ariès (2006) -, coloca cada criança no centro de interesse do processo social, como única e específica, individualidade autônoma e sem paralelo. Já o processo de socialização, atuando por meio de diferentes instâncias - igreja, escola, família, grupo de pares, mídia, para citar algumas -, estabelece espaços normativos nos quais os indivíduos irão apreender a materialidade e o simbólico, mas que não são únicos, e sim herméticos e múltiplos. São instituiçôes que atuam na socialização das crianças e caracterizam profundamente a vida delas, marcando as maneiras de agir e de pensar quando se está em interação com outros e com seu meio circundante (DANIC, 20II). Se o processo de socialização se desenvolveu a partir de uma perspectiva funcionalista estrutural - tendo como principais teóricos Émile Durkheim, Talcott Parsons e Robert Bales -, na atualidade o debate é marcado por práticas sociais, relações de poder e condiçôes de existência, que contribuem para a construção de disposiçóes individuais que orientam os modos de participação na vida social. (ABRANTES, 20II)

Esses processos - individualização e socialização - se imbricam continuamente, pois ao passo que a criança emprega e apreende as características, as normas e o enredamento sociocultural, essa mesma sociedade sofre com as interferências desse outro modo de apreensão e de seus agires. Em uma interpretação pautada em Agamben (2005), podemos inferir que na medida em se possui infância não é possível se apropriar da cultura sem transformá-la. Assim, se há a necessidade de intervenção da sociedade so- 
bre a criança também há expectativas e transformaçóes a partir das açóes delas. E esse constante desacordo entre o indivíduo livre e aquele a ser socializado gera a tensão e o conflito entre a intervenção e a autonomia, pois normas, valores e açóes determinados socialmente devem orientar e formar as pessoas que são singulares e independentes. (BARALDI, 200I, I997; SETTON, 20I ; DUBET, I994)

Socializar-se é educar-se e, em geral, inicia-se com a família, visto que ali as crianças estabelecem suas primeiras relaçóes e interaçóes sociais, as quais são mais horizontais e subordinadas aos discernimentos emocionais, simbólicos e econômicos. De acordo com Sirota (2007, p. 44), é uma socialização horizontal, dado que "Não estamos mais num esquema vertical descendente, não existe um ir-e-vir, uma reversibilidade do processo. Ofício de criança e ofício de pais se constroem em paralelo [...]" Tanto pais quanto responsáveis pelas crianças investem na educação e na proteção delas, e a afetividade é um elemento característico dessa instância, a qual tende a individualizar as ações dos seus membros.

Para as crianças, suas famílias são um espaço de proteção, estima e distinção entre seus membros, e elas reconhecem o conjunto de regras e sançóes estabelecidas pelos adultos, jovens e velhos. Elas aprendem que dentro da esfera familiar há certas regras que os adultos não negociam e que outras estão abertas à negociação (MONTANDON, 2005). Ainda assim, elas questionam e transgridem as normas estabelecidas por pais e familiares, indicando sua agência no grupo. Essa articulação que cada criança deve reorganizar a partir do processo de socialização revela "[...] uma introspecção notável sobre seu próprio modo de aprender e de interagir com os outros." (op. cit., p. 495) E esse processo de negociação, agora mais democrático, pautado na comunicação e no diálogo, alimenta e reforça os laços de interdependência entre filhos, pais e/ou responsáveis, o que não significa perda de autoridade dos adultos, mas novos modos de compromisso. É um aspecto importante, pois perante a pluralidade de disposiçôes, habilidades e contextos as crianças vivem cada vez mais frequente e precocemente situaçôes sociais heterogêneas e, às vezes, contraditórias (LAHIRE, 2006). Diante das novas feiçôes, os membros de uma família precisam constantemente rever suas açóes, valores e discursos, já que, enquanto instituição, ela não está isolada na esfera social; ao contrário disso, é mutante e está vinculada aos sujeitos e a muitas outras esferas, como a 
escola, o trabalho, a mídia e a religião. No bojo dos múltiplos processos socializadores vividos pelas crianças, é fato que elas crescem em um mundo no qual a mídia penetra e domina suas vidas; a mídia atua enquanto instância que difunde produtos, imagens, discursos e práticas (HENGST, 1997). Também é fato que a mídia é esse aparato de meios comunicacionais, digitais ou analógicos, com finalidades informacionais, comerciais, repercussão da/na opinião pública; com redes de complementariedades e de desenvolvimento de novas tecnologias que acabam por adequar seus produtos - material e simbólico - a públicos específicos. É uma instituição que penetra e faz reverberar na sociedade aspectos das políticas e dos entendimentos socioculturais construídos. Porém, como nos adverte Lúcia Santaella (2003, p. II7), "[...] considerar que as mediaçóes sociais vêm das mídias em si é incorrer em uma ingenuidade e equívoco epistemológicos básicos, pois a mediação primeira não vem das mídias, mas dos signos, linguagem e pensamento, que elas veiculam." São, portanto, elementos da cultura, com os quais as crianças aprendem a lidar e que possibilitam acesso aos produtos e às mensagens midiáticas, já que são participantes da sociedade e trocam informaçóes com diversas pessoas.

Ocorre ainda considerar que a sacralização das crianças - conceito elaborado por Viviana Zelizer (I994) e fundamentado nas mudanças sociais - faz com que os pais e/ou responsáveis muitas vezes compensem as horas a menos passadas com os filhos disponibilizando o acesso ao consumo e à mídia. Sabemos que há pouco ou quase nenhum reconhecimento social das crianças na produção econômica, mas para o aparato midiático elas produzem recursos ao consumirem uma produçáo de mercadorias e serviços destinada à infância. Se a mídia produz e difunde para a infância uma série de produtos e discursos, entendemos que elas são usuárias e consumidoras desses produtos serviços e, em razão de espaços mais democráticos - a exemplo do meio familiar, onde têm liberdade para interferir nas escolhas da família, indicando, sugerindo e requerendo aquilo que a mídia oferta. Certamente essas escolhas ocorrem num dado contexto relacional e funcional entre pais e filhos, permeado por relações afetivas, condiçóes econômicas, interação para interpretação e compreensão dos signos, linguagens e pensamento, e pelas normas educativas fundamentadas na idade, no sexo, na raça e no local de moradia. 
Considerando essas duas grandes instâncias de socialização, inferimos que a educação não é um processo de mão única, pois as crianças são atuantes, participam, se expressam, falam, refletem e colocam suas ideias de diferentes formas; usam seu conhecimento para tomar decisóes, entender os fatos e produzir modificaçóes nas rotinas, nas normas e nos valores, sejam os dados pela família sejam os que frequentam a mídia. Sendo assim, as açôes e as falas infantis jamais são naturais ou destituídas de sentidos, mas são organizadas a partir das suas vivências em diferentes contextos e de acordo com suas experiências na sociedade e na cultura. Contudo, cabe relembrar, considerando os estudos de Berger (I986), que as instituiçôes são um complexo específico de ações sociais, uma criação humana que proporciona métodos, normas e regras pelos quais a conduta humana é padronizada e desejável à sociedade, obrigando os indivíduos a caminhos que pareçam os únicos possíveis. Se há liberdades, ainda é dentro de certos limites. Com essas proposiçóes em mente torna-se mais fácil refletir sobre as interações ocorridas na escola de educação infantil e nos seus grupos de pares.

\section{Criança, seus grupos de pares e escola de educaçáo infantil: espaços e tempos de sociabilidades e participação democrática}

Os estudos da infância proclamaram outra reconstrução da infância, que passou a ser entendida como categoria que estrutura a sociedade, e outra concepção de criança, como ator social digno de estudo em seu direito próprio (PROUT; JAMES, I990). Essa mudança teórica-conceitual desenvolvida nas pesquisas acadêmicas repercutiu e impactou nas práticas pedagógicas, na sociedade civil e nas políticas públicas de atendimento à infância. De um modo geral, passamos a ver na documentação pedagógica-legal, nas reinvindicaçóes de movimentos sociais e no discurso daqueles que estão envolvidos com a infância expressóes como protagonismo infantil, crianças como sujeitos de direitos, reconhecer o direito de fala das crianças, cultura das crianças, entre outros. Para citar um exemplo, a Resolução no 5, que define as Diretrizes Curriculares Nacionais para a Educação Infantil (BRASIL, 2009), considera a criança 
Sujeito histórico e de direitos que, nas interações, relaçôes e práticas cotidianas que vivencia, constrói sua identidade pessoal e coletiva, brinca, imagina, fantasia, deseja, aprende, observa, experimenta, narra, questiona e constrói sentidos sobre a natureza e a sociedade, produzindo cultura.

Entretanto, a escola, por ser uma instituição social, é regida por normas estabelecidas e ajustadas pelo poder público e a administração institucional, o que a torna uma instância educativa formal. Esse mesmo poder que estrutura a dinâmica da escola de certo modo interfere na constituiçáo da infância e na construção dos grupos infantis, pois a escola os organiza de acordo com determinados parâmetros e trabalha com concepçôes de infância. Ainda assim, na atualidade, é sobretudo na escola que as crianças vivem relaçôes socioculturais constituídas com seus pares e também participam de um espaço e tempo construídos pelos adultos para elas.

Todavia, a educação infantil no Brasil tem como marca a desigualdade, a qual reflete nas práticas pedagógicas, nas concepçóes educacionais e nas políticas públicas. Se de um lado temos

[...] uma legislação avançada que reconhece direitos a todas as crianças; de outro, um panorama de intensas desigualdades entre as idades e os diferentes segmentos sociais, dificultando, na prática, o reconhecimento pleno de sua cidadania. [...] Esse descompasso entre "o Brasil legal e o Brasil real" poderia ser explicado pelo fato de o país ser pobre. Mas, conforme economistas, o Brasil não é um país pobre, mas um país com intensa desigualdade econômica e social, com grande número de pobres. (ROSEMBERG, 20I2, p. I9-20)

Para a autora, há uma dívida brasileira para com suas crianças, a qual não decorre apenas da desigual distribuição de rendimentos entre os segmentos sociais, mas também pela desigual distribuição de benefício das políticas públicas, desigualdade sustentada por gastos per capita também desiguais na comparação entre segmentos etários, no acesso à educação conforme a raça-etnia, classe social, gênero e local de moradia. (id.ib.) 
Ainda que a situação da infância brasileira não seja simples, a escola de educação infantil brasileira tem enorme importância para as crianças. Creche e pré-escola constituem espaços de produção humana, socialização, sociabilidades, cuidado e atuação da infância, já que ali as crianças são reunidas e interagem com seus pares e dão expressão às suas sociabilidades (CÂNDIDO, I969). É pela e na escola que elas têm acesso ao patrimônio cultural produzido pela humanidade e a seus valores e normas sociais. É também nessa instituição que, nas interaçôes com seus pares - entre bebês e crianças pequenas - e com os adultos tanto se contribui para a manutenção de aspectos da cultura quanto se transformam e se produzem outras ideias, discursos e práticas. Portanto, a experiência de participar de grupos não é algo novo para as crianças; o que é novo é a possibilidade de constituir o seu próprio grupo e uma cultura própria, ainda que organizados dentro de uma estrutura social já estruturada - a escola.

Ao participar de um grupo de pares as crianças têm a possibilidade de criar, reorganizar e conduzir as regras e os valores que refletem os seus interesses e, assim, podem expressar abertamente seus entendimentos da cultura e os atributos que dão sentido às suas infâncias. Portanto, os grupos de pares são importantes, pois "[...] afirmam-se por comportamentos que buscam expressar e legitimar identidades, numa luta pela significação.” (PAIS, 2008, p. 209) Significação que vai se conformando em ações e reverbera em situaçóes como as relatadas no início deste texto. De um lado, a escola de educação infantil representa um espaço de cultura para as crianças, com materiais e símbolos produzidos pelos adultos para a infância; de outro, ela é um espaço de sociabilidades e um espaço da infância, onde as crianças desenvolvem uma cultura peculiar que é sua própria expressão. Vale observar que o acesso ao patrimônio cultural e à sociabilidade não se dão de modo igual para todas elas, uma vez que as desigualdades econômicas, sociais e culturais existentes na sociedade brasileira atravessam suas vivências, podendo produzir experiências de rejeição social e de não reconhecimento identitário. (AQUINO, 2013)

De qualquer modo, os grupos de pares figuram um lugar de destaque na vida das crianças, pois é por eles que se dá a construção da ação social da infância. Essa açáo envolve um processo amplo, complexo, difuso e, principalmente, não dicotômico entre o indivíduo e a sociedade, entre o particular e o coletivo, pois cada criança pode vir a participar de vários 
grupos de pares e, na relação entre elas, cada uma tanto acrescenta algo de si quanto acolhe o que circula no espaço social.

As famílias contemporâneas têm se configurado, cada vez mais, nucleares e residentes em lugares que não possibilitam o encontro frequente entre crianças de diferentes famílias. A convivência quase exclusiva com adultos e a ausência de espaços onde haja condiçóes de interação entre pares sem o controle direto dos adultos sobre suas açóes e escolhas, têm tornado mais relevante a escola de educação infantil. Nesse sentido, a relação entre crianças expóe as produções, as influências mútuas, os valores, os interesses, os desagrados e os julgamentos infantis a respeito dos processos vividos nas diferentes instâncias de socialização. Aqui se destaca a responsabilidade das escolas de educação infantil no sentido de garantir o encontro entre as crianças e os seus modos de agir no mundo, visto que elas se utilizam da ludicidade para estruturar suas interaçôes e compreensóes. É pelo lúdico, mas não exclusivamente, que as crianças são autoras e coprodutoras de um espaço de sentido e experiência que exige sua ação, a qual é determinada por ela, mas deve considerar os outros elementos e sujeitos envolvidos.

Dessa forma, os grupos de pares podem ser abertos ou fechados, pequenos ou grandes, temporários ou permanentes, localizados ou dispersos, solidários ou antagônicos, formais ou informais, mas em qualquer dos casos há sempre açôes recíprocas e influxos mútuos que são estabelecidos entre as crianças (PAIS, 2008). E o processo de socialização entre pares tem seus determinantes, suas regras e valores, mas com um caráter muito mais difuso, assistemático e inconsciente, o que garante interaçóes menos hierárquicas, portanto, mais igualitárias, além de maior possiblidade de negociaçôes, embora atravessadas por elementos sociais estruturantes como as relaçóes de gênero, de classe, de raça etc., como observado desde o estudo de Florestan Fernandes (2004), na década de 1940. Claro que as propriedades indicadas pelo grupo de pares mostram articulaçôes e produçôes de sentidos das crianças relacionados aos processos de socializaçáo familiar, escolar e midiático, por exemplo; no entanto, as interaçóes no grupo de pares envolvem cada indivíduo, todo o grupo, a família, a escola e a mídia.

A relevância da educação infantil na sociedade contemporânea está associada à composição familiar, progressivamente predominando o modelo nuclear e o fato de residirem em lugares que não possibilitam o en- 
contro e a constância entre crianças de diferentes famílias. Essa realidade demanda que se garanta às crianças condiçôes para que haja interação e convivência sem o controle permanente e direto dos adultos sobre suas açôes e escolhas, o que se caracteriza como um desafio para as escolas, desde a educação infantil.

\section{Consideraçóes finais}

Os processos de socialização são fatos para toda e qualquer pessoa, mas que não terminam quando se sai da infância. Como já nos disse Guimarães Rosa (2006, p. 03), “o mais importante e bonito, do mundo, é isto: as pessoas não estáo sempre iguais, ainda não foram terminadas - mas que elas vão sempre mudando." As crianças também vão mudando conforme as exigências postas por esse mundo a elas e conforme seus entendimentos de mundo. Contudo, elas também têm exigindo dos adultos uma real educação democrática, na qual possam realmente ser partícipes, pelo menos nas questóes e espaços em que estão presentes e que as envolvem, como na escola e na família.

Após um período de avanços e conquistas sociais para a infância, ainda que a passos lentos, depois da promulgação da Constituição Cidadá (BRASIL, I988), os últimos anos, desde o golpe do impeachment, em 20I6, foram de enormes retrocessos e estagnação econômica e cultural. Arroyo (2015, p. 20), em seu artigo $O$ direito à educação e a nova segregação social e racial - tempos insatisfatórios?, indaga se naquele momento estamos "em tempos de avanços ou recuos no seu [crianças, adolescentes e jovens] reconhecimento como sujeitos do direito à educação atrelado à afirmação dos direitos humanos." Evidencia em sua análise a compreensão do crescimento dos mecanismos de controle e repressão às lutas no campo dos direitos humanos por grupos tradicionalmente excluídos - pobres, trabalhadores, negros, indígenas, quilombolas, camponeses e também crianças, adolescentes e jovens. No ano de 2019, é evidente que a resposta a tal indagação é de que o tempo é de forte recuo, tanto pelas medidas econômicas adotadas quanto pela orientação conservadora e autoritária assumida na condução do Estado e em sua relação com os grupos sociais subalternizados e oprimidos historicamente. 
Entretanto, mesmo com os atuais retrocessos, existe "uma tensão entre afirmação e negação dos direitos humanos", como analisa Arroyo (id.ib., p. I5), que se tem intensificado por meio de "medidas de controle e repressão às suas lutas", havendo reação e "presença afirmativa dos coletivos sociais." E as crianças são sujeitos desses coletivos que resistem e cobram o direito à participação nas tomadas de decisão que afetam suas vidas. Assim, talvez em uma curiosa inversão política, as crianças, como as que foram indicadas inicialmente neste texto, vêm, de modo direto ou indireto, exigindo uma educação ativa, democrática, que garanta uma formaçâo social, política e ética por todos (e para todos) da sociedade. Elas têm exigido participação na vida pública. Nos termos de Maria Victória Benevides (1996, p. 230), uma educação democrática significa estar pautada em: a) leis que precisam ser decididas em processos regulares e amplamente participativos; b) respeito ao bem público, acima do interesse privado e patriarcal; c) sentido de responsabilidade no exercício do poder.

A discussão sobre a possibilidade de participação das crianças na esfera pública tem se colocado em estudos acadêmicos mais recentemente, embora a presença e atuação infantis, em diferentes contextos de disputa política, se registre há muito na história contemporânea (GONÇALVES, 2018; MACEDO, 2016), tensionando o processo de afirmação dos direitos das crianças, que desde os meados do século XX tem se caracterizado mais em seus aspectos de proteção e tutela do que de direito à participação (FERRERI, 2009). As crianças, com os adolescentes e os jovens, questionam as leis e os regimentos do Estado e das instituiçóes que frequentam, questionam a ordem patriarcal e privada e reivindicam assumir responsabilidades nas diversas instâncias e esferas de exercício do poder, aspectos que pautam uma educação democrática, como já mencionado.

Alguns movimentos são emblemáticos na história recente do país. $\mathrm{Na}$ década de 1980, se organizou o Movimento Nacional de Meninos e Meninas de Rua (MNMMR), mobilizado em diversas cidades, que contribuiu para o "reconhecimento da criança e do adolescente como sujeitos de direitos e protagonistas da sua própria história." O MNMMR participou do processo constituinte que se dava então, tendo elaborado documento que "ganhou uma adesáo enorme e por conta disso conseguiram apresentar uma ementa com mais de um milhão de assinaturas" (SOUZA, s/d, p. 8), que resultou no artigo 227 da Constituição Federal de I988: 
É dever da família, da sociedade e do Estado assegurar à criança e ao adolescente, com absoluta prioridade, o direito à vida, à saúde, à alimentação, à educação, ao lazer, à profissionalização, à cultura, à dignidade, ao respeito, à liberdade e à convivência familiar e comunitária, além de colocá-los a salvo de toda forma de negligência, discriminação, exploração, violência, crueldade e opressão. (BRASIL, I990)

Do artigo 227 da Constituição se criou o Estatuto da Criança e do Adolescente (ECA), Lei no 8069, que igualmente contou com a mobilização desse Movimento e apoio da população (SOUZA, s/d). O ECA traz um conjunto de princípios e medidas de proteção, mas também afirma o direito à expressão e participação das crianças e adolescentes, configurando-se instrumento de defesa da presença desses sujeitos em manifestaçóes e atos públicos, como ocorrido em 20I4, na cidade do Rio de Janeiro, descrito abaixo:

[...] movimento "Advogados Ativistas" [...] publicou em sua página na internet a notícia: "Justiça do RJ concede salvo conduto a crianças e adolescentes em manifestação". O salvo conduto, foi um habeas corpus preventivo, para um grupo de crianças e adolescentes que, acompanhados de seus familiares, acampavam em frente à prefeitura da cidade do Rio de Janeiro, depois de serem desalojados por ordem judicial de reintegração de posse do terreno em que moravam na denominada "Favela do Oi”. O objetivo do habeas corpus era que as crianças e jovens menores de idade não fossem levados a abrigos e afastados de suas famílias. Percebe-se aqui a contradição e a ambivalência com que a infância é tratada em nossa sociedade. Sob a argumentação de proteger as crianças, que estavam desabrigadas por uma ação do próprio Estado, a polícia teve a intenção de retirá-las de perto dos seus entes queridos, levando-as a abrigos e instituiçóes para menores, cerceando seus direitos e impedindo-as, da participação como cidadãs, de manifestar-se em espaço público. (MACEDO; AQUINO, 20I6, p. 872) 
A presença de crianças em atos políticos e movimentos de resistência tem sido registrada pela mídia e em estudos acadêmicos, seja em contextos urbanos ou rurais, em movimentos de esquerda ou de direita, nos movimentos negro, indígena, de mulheres, ou ainda de defesa da educação, como o Movimento dos Fraldas Pintadas (2005-2007) (MACEDO; AQUINO, 20I6). Nesses atos observam-se crianças empunhando cartazes e faixas, alguns deles elaborados pelas próprias previamente ou durante as oficinas de confecção de material que muitas vezes se realizam nas próprias concentraçóes.

No cenário nacional e mesmo no internacional, os Sem Terrinha têm representado referência para pensar o direito à participação das crianças, não só em manifestações, mas também na formulação de pautas e açóes destinadas a elas e à sociedade como um todo, quando trazem em suas reivindicaçóes, por exemplo, a defesa da alimentaçáo saudável e da brincadeira, e o lazer como direito das crianças, como evidenciado no documento encaminhado à Coordenação Nacional do MST, em nome de todos os Sem Terrinha, com as ideias das próprias crianças para o Encontro Nacional dos Sem Terrinha em 2018:

- Que o encontro nacional dos Sem Terrinha possa ser pensado e construído por nós com o apoio dos adultos.

- Que seja um espaço alegre, recreativo, esportivo e que seja do nosso jeito.

- Que as palestras não sejam chatas, mas com muita arte e alegria conduzida por nós.

- Nós Sem Terrinha assumiremos nossas responsabilidades: com a divisão de tarefas práticas, coordenação dos dias e noites culturais.

- Queremos também, que nosso encontro tenha uma alimentação saudável e orgânica. (RAMOS, 20I9, p. 87)

Terminamos este ensaio, propositadamente, com a canção/hino produzida pelos Sem Terrinha do Rio de Janeiro, que ganhou expressão nacional, na qual crianças de todos os estados cantam com muita propriedade: "Sou Sem Terrinha do MST, acordo todo dia para lutar, você vai ver! Por terra, por escola, saúde e educação, desse meu direito eu não abro mão", como registrado na pesquisa de Ramos. (2019, p. 85) 


\section{Bibliografia:}

ABRANTES, P. Para uma teoria da socialização. Sociologia, Revista da Faculdade de Letras da Universidade do Porto, vol. XXI, 20I I, p. I2I-I39.

AGAMBEN, G. Infância e história: destruição da experiência e origem da história. Belo Horizonte: Editora UFMG, 2005.

ALANEN, L. Estudos feministas/Estudos da infância: paralelos, ligaçóes e perspectivas. In: CASTRO, L. R. de (org.). Crianças e jovens na construção da cultura. Rio de Janeiro: NAU; Editora: FAPERJ, 200 .

AQUINO, L. M. L. Infância e diversidade nas orientações nacionais para a educação infantil. In ABRAMOWICZ, A.; VANDENBROECK, M. (org.). Educação Infantile diferença. Campinas/SP: Papirus, 2013. pp. 169-187.

ARIÈS, P. A história social da criança e da família. Rio de Janeiro: LTC, 2006.

ARROYO, M. G. O direito à educação e a nova segregação social e racial - tempos insatisfatórios? Educação em Revista. Belo Horizonte, v.3I, n. 3, Julho-Set. 2015, p. I5-47.

BARALDI, C. Un bambino piange: L'educazione e la cultura dell'infanzia nella società contemporanea. Rassegna Italiana di Sociologia. Bologna: Il Mulino, ano XLII, n. o3, lug./set., 200I, p. 453-483.

BARBOSA, M. C. S.; DELGADO, A. C. C.; TOMÁS, C. A. Estudos da infância, estudos da criança: quais campos? Quais teorias? Quais questóes? Quais métodos? Inter-Ação, Goiânia, v. 4I, n. I, jan./abr., 2016, p. I03-I22.

BASTIDE, R. Prefácio. FERNANDES, F. As “Trocinhas” do Bom Retiro: contribuiçáo ao estudo folclórico e sociológico da cultura e dos grupos infantis. Pro-posiçôes, Campinas, vol. I5, nº. 43, jan./abr. 2004. p. 229-23I.

BENEVIDES, M. V. Educação para a democracia. Lua Nova, nº. 38, dez./1996, p. 223-237.

BERGER, P. L. Perspectivas sociológicas: uma visão humanística. Petrópolis: Vozes, I986. BOURDIEU, P. Razóes práticas: sobre a teoria da ação. Campinas: Papirus, I996.

BRASIL. Constituição da República Federativa do Brasil. Brasília: Senado, I988.

BRASIL. Lei no 8.069, de I3 de julho de I990. Dispóe sobre o Estatuto da Criança e do Adolescente e dá outras providências. Disponível em: <http://www.planalto.gov.br/ ccivil_03/leis/L8069.htm>. Acesso em: 04/05/2017.

BRASIL. Conselho Nacional de Educação. Câmara de Educação Básica. Resolução no 05, de 17 de dezembro de 2009. Diretrizes Curriculares Nacionais para a Educação Infantil. Disponível em: <http://www.mec.gov.br/cne/pdf/>. Acesso em janeiro de 20 Io. 
CÂNDIDO, A. A estrutura da escola. In: PEREIRA, L.; FORACCHI, M. M. Educação e sociedade: leituras de sociologia da educação. São Paulo: Editora Nacional, I969.

DANIC, I. Socialização Escolar. In: ZANTEN, A. V. Dicionário de Educação. Petrópolis, RJ: Vozes, 20II.

DUBET, F. Sociologia da experiência. Lisboa: Instituto Piaget, I994.

FERNANDES, F. As “Trocinhas” do Bom Retiro: contribuição ao estudo folclórico e sociológico da cultura e dos grupos infantis. Pro-posiçóes, Campinas, vol. I5, nº. 43, jan./abr. 2004, p. 229-23I.

FERRERI, M. A. Educação e direito no "século da criança": a consolidação da internacionalização da infância. NEVES, P. S. C. (org.) Educação e cidadania: questôes contemporâneas. São Paulo: Cortez, 2009, p. I34-I59.

FREIRE, P. Alfabetização e cidadania. Revista de Educação Municipal. Ação Direta: UNDIME, Cortês Editora, São Paulo, ano oI, nº. oI, jun., I988, p. o6-I5.

GONÇALVES, B. O. Sorrisos infantis na luta pela terra: A participação das crianças na vida política da sociedade. Dissertação de Mestrado. Rio de Janeiro: UERJ, 20 I8.

HENGST, H.. Reconquering urban spots and spaces? Children's public(ness) and the scripts of media industries. Childhood. SAGE: vol. 04, no. 04, nov., I997, p. 425-444.

LAHIRE, B. A cultura dos indivíduos. Porto Alegre: Artmed, 2006.

MACEDO, E. E. Crianças pequenininhas e a luta de classes. Tese de Doutorado. Campinas/SP: Unicamp, 2016.

MACEDO, E. E.; AQUINO, L. M. L. A participação e contribuiçôes das crianças nos movimentos sociais. III International Conference Strikes and Social Conflicts: combined historical approaches to conflict. Proceedings. CEFID-UAB, 20I6. Disponível em https:// ddd.uab.cat/pub/caplli/20I6/I58336/RZS63UMacedo_Elina_Aquino_Ligia_OK_.pdf. Acesso em 21/05/2019.

MONTANDON, C. As práticas educativas parentais e a experiência das crianças. Educação e Sociedade. Campinas, col. 26, nº. 91, maio/ago., 2005, p. 485-507.

MOVIMENTO NACIONAL DE MENINOS E MENINAS DE RUA. Psicol. cienc. prof. [online]. I988, vol.8, n.I, pp. I4-I 4. Available from: <http://www.scielo.br/scielo. php?script=sci_arttext\&pid=SI 4I 4-98931988000100007\&lng=en\&nrm=iso $>$. ISSN I 4I 4-9893. http://dx.doi.org/IO.I590/SI4I 4-9893I988000I00007.

PAIS, J. M. Culturas de Grupo. In: LAGES, M. F.; MATOS, A. T. de (coord.). Portugal: recursos de interculturalidade. Contextos e dinâmicas. Vol. II, Lisboa: Alto-Comissário para a Imigração e Diálogo Intercultural, 2008.

PROUT, A.; JAMES, A. A new paradigm for the sociology of childhood? Provenance, promise and problems. JAMES, A.; PROUT, A. (eds.). Constructing and reconstructing childhood: contemporany issues in the sociological study of childhood. Basingstoke: Falmer Press, I990. 
QVORTRUP, J. A infância enquanto categoria estrutural. In: Educação e Pesquisa. São Paulo, vol. 36, nº. 2, maio/ago., 2010 a, p. 63I-643.

RAMOS, M. M. Infância do campo: uma análise do papel educativo da luta pela terra e suas implicaçôes na formação das crianças do MST. Trabalho de Qualificação de Doutorado. Programa de Pós-graduação em Educação. Rio de Janeiro: UERJ, 2019.

ROSA, J. G. Grande Sertão Veredas. Rio de Janeiro: Editora Nova Fronteira 2006.

ROSEMBERG, F. Educação para quem? Ciência e Cultura (SBPC), vol. o2, nº. I2, I978, p. I466-I 47 I.

ROSEMBERG, F. A criança pequena e o direito à creche no contexto dos debates sobre infância e relações raciais. In: MINISTÉRIO DA EDUCAÇÃO, CEERT, UFSCar/ NEAB. Educação infantil, igualdade racial e diversidade: aspectos políticos, jurídicos, conceituais. São Paulo: Centro de Estudos de Relaçóes de Trabalho e Desigualdades CEERT, 2012.

SANTAELLA, L. Culturas e artes do pós-humano: da cultura das mídias à cibercultura. São Paulo: Paulus, 2003.

SETTON, M. G. J. Teorias da socialização: um estudo sobre as relações entre indivíduo e sociedade. Educação e Pesquisa. Sáo Paulo, vol. 37, nº. 04, dez., 20I I, p. 7I I-724.

SIROTA, R. A indeterminação das fronteiras da idade. Perspectiva, Florianopólis, vol. 25, n. OI, jan./jun., 2007, p. 4I-56.

SOUZA, T. J. O Movimento Nacional de Meninos e Meninas de Rua e a conquista dos direitos: $\mathrm{O}$ marco do movimento social em prol da garantia dos direitos da criança e do adolescente no Brasil. III Simpósio Mineiro de Assistentes Sociais. Belo Horizonte/MG: CRESS, s/d. Disponível em: http://www.cress-mg.org.br/arquivos/simposio/O\%2o MOVIMENTO\%20NACIONAL\%20DE\%20MENINOS\%20E\%20MENINAS\%20 DE\%2oRUA\%2oE\%2oA\%2oCONQUISTA\%2oDOS\%2oDIREITOS.pdf . Acesso em 20/05/2019.

ZELIZER, V A. Pricing the priceless child. The changing social value of children. Princeton/New Jersey: Princeton University Press, 1994.

Recebido em 5 jun. 20I9 / Aprovado em 4 set. 2019

Para referenciar este texto:

GOMES, L. O.; AQUINO, L. M. L. Crianças e infância na interface da socialização. Questóes para a educação infantil. EccoS - Revista Científica, São Paulo, n. 50, eI 4092, jul./set. 2019. Disponível em: https://doi.org/I0.5585/EccoS. n50.14092. 